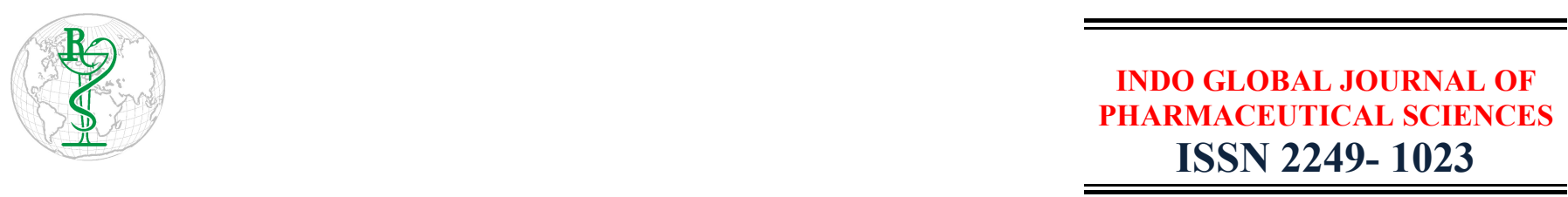

\title{
Anti-Inflammatory Effect of Neuracanthus Sphaerostachyus Dalz. Leaves on Experimental Colitis in Rats
}

\author{
Dangar DK ${ }^{1}$, Patel NJ *2 \\ ${ }^{1}$ Ganpat University, Ganpat Vidyanagar, Gujarat-384012, India \\ ${ }^{2}$ Department of Pharmacology, S. K. Patel College of Pharmaceutical Education \& Research, Ganpat University, Ganpat Vidyanagar, Gujarat- \\ 384012, India
}

Address for Correspondence: Patel NJ, nilesh.patel@ganpatuniversity.ac.in ;

nileshcology127@yahoo.co.in

\begin{abstract}
Received:
11.07.2019

Accepted:

04.01.2020

Published:

30.03.2021

Keywords

Neuracanthus

sphaerostachyus,

Inflammatory

Bowel Disease, Ulcerative colitis, tri-nitro benzene sulphonic acid, Myeloperoxidase Tumor necrosis factor- $\alpha$.
\end{abstract}

\begin{abstract}
Inflammatory bowel disease (IBD) is a chronic idiopathic inflammatory disorder with unknown etiology affecting the GI tract. Neuracanthus sphaerostachyus has been traditionally used for the treatment of skin diseases, cough, and asthma in various forms orally. Lack of sufficient scientific evidence indicating the utility of this plant in the treatment of ulcerative colitis prompted us to investigate the antiinflammatory activity of the plant on experimental colitis in rats. In-vivo pharmacological screening method for evaluation of anti-inflammatory activity of the methanolic and aqueous extract of Neuracanthus sphaerostachyus leaves at doses of 125,250 , and $500 \mathrm{mg} / \mathrm{kg}$ was assessed by TNBS-induced ulcerative colitis in Wistar rats. Colitis was induced by intra-rectal instillation of $10 \mathrm{mg}$ of tri-nitro benzene sulphonic acid (TNBS) in $0.25 \mathrm{ml}$ of $50 \%$ ethanol (v/v) followed by treatments with $7 \mathrm{~d}$ for various extracts and then animals were sacrificed to remove colon for histopathology, macroscopic scoring, and biochemical assays. The $7 \mathrm{~d}$ treatment with a methanolic and aqueous extract of Neuracanthus sphaerostachyus significantly improved feed intake and body weight with a decrease in macroscopical score, colonic MPO, LPO and, TNF- $\alpha$. The findings from the histopathological study support the above results by its potential to protect the colonic mucosal damage. The present study exhibits anti-inflammatory potential of methanolic and aqueous extracts of Neuracanthus sphaerostachyus leaves in TNBS induced experimental colitis and it can be beneficial for patients suffering from ulcerative colitis. (C) 2020 iGlobal Research and Publishing Foundation. All rights reserved.
\end{abstract}

Cite this article as: Dangar, D.K.; Patel, N.J. Anti-inflammatory effect of Neuracanthus Sphaerostachyus Dalz. leaves on experimental colitis in rats. Indo Global J. Pharm. Sci., 2021; 11(1): 7-14. DOI: http://doi.org/10.35652/IGJPS.2021.111002 .

\section{INTRODUCTION}

Inflammatory bowel disease (IBD) is a chronic, idiopathic inflammatory disorder of intestine. Inflammatory bowel disease comprises of the crohn's disease (CD) and ulcerative colitis (UC) with their unique features. Ulcerative colitis mainly confined to colonic inflammation whereas Crohn's disease may involve any part of the gastrointestinal tract from the mouth to the anus [1]. Etiology of IBD is still not known, but current literature survey revealed that it may involve multiple factors like gene modulation, oxidative stress, infectious agents, immune reactions and microorganism. CD and UC may be seen in different socioeconomic stages with western lifestyle and incidences can be seen at a higher rate in developed countries than developing countries. These factors may represent inflammation in mucosa, hemorrhage and, ulcers in a colon. Initiation and progression of IBD depend on the generation of the free radicals during the progression of the disease and may contribute to the development of cancer. Current therapeutics approaches involve treatment with immunosuppressants and 5-aminosalicylic acid for symptomatic or temporary relief with toxic side effects associated with their use. Therefore, it is essential to develop 


\section{Indo Global Journal of Pharmaceutical Sciences, 2021; 11(1): 7-14}

alternative therapeutic agents with higher efficacy and safety for the treatment of IBD [2 -4].

Neuracanthus sphaerostachyus Dalz is commonly known as Ghoswel(Hindi), Golgonda(Marathi) and Ganthera Gandharo(Gujarati). Plant belongs to Indian regions and widely distributed in Western Ghats, Deccan and Gujarat [5]. This plant is traditionally used in different areas of Western Ghats. Root extract is used to treat rheumatoid arthritis. Fruits, flowers and seeds are given for the treatment of diabetes. The mixture of ash of the whole plant with jaggery or honey is used 2 to 3 times a day orally to cure cough and asthma [6]. It is also administered in paste form in the cases of indigestion. Previous studies with Neuracanthus sphaerostachyus shows the presence of vanillic acid, syringic acid, melilotic acid and 6-OH luteolin [7].

\section{MATERIALS AND METHODS}

\section{Collection and Authentication of plant}

Neuracanthus sphaerostachyus Dalz. leaves were collected from Girnar forest region of Junagadh, Gujarat. Plant material was authenticated by NISCAIR-CSIR (National Institute of Science Communication and Information Resources), New Delhi. (NISCAIR/RHMD/Consult/2016/2987-14)

\section{Extraction of plant material}

Extractive values of crude drugs were used to determine the number of active constituents extracted with solvents from a given amount of medicinal plant material. The successive extraction was carried out in soxhlet apparatus with a known quantity of powder in different organic solvents like Hexane, chloroform, methanol and then water. After exhaustive extraction, the solvent was filtered and concentrated under reduced pressure at $50-55^{\circ} \mathrm{C}[8]$.

\section{Chemicals}

Prednisolone and tri-nitro benzene sulphonic acid were procured from Merck, India. All the chemicals and reagents used were of analytical grade.

\section{Animals}

Female Wistar rats (150-200 g) were used for the study. The animals were kept in polypropylene cages and maintained at a temperature of $26 \pm 2^{\circ} \mathrm{C}$. Animals were fed with diet provided by Pranav agro-industries Ltd., Sangli. Feed was composed of crude proteins $(18.05 \%)$, crude fat $(3 \%)$, crude fiber $(4.25 \%)$, calcium $(1.15 \%)$, phosphorus $(0.52 \%)$, total ash $(5.75 \%)$ and carbohydrates (63\%). All the animal experiments were conducted in accordance with the guidelines of the CPCSEA (Reg. No. 1846/PO/RE/s/16/CPCSEA), a guide for the care and use of laboratory animals. The animals were acclimatized for 10 days under standard husbandry conditions as Relative humidity $45-55 \%$, and $12 \mathrm{~h} \mathrm{light} \mathrm{and} \mathrm{dark} \mathrm{cycle} \mathrm{[9].}$

\section{Acute toxicity study}

Female Wistar rats of 150 - 200g body weight were selected to find out the acute toxicity study of a methanolic and aqueous extract of Neuracanthus sphaerostachyus leaves. The dose of $2000 \mathrm{mg} / \mathrm{kg}$ was selected on the basis of Up and Down Procedure (UDP) as per OECD Guideline No.425. All animals were observed for $24 \mathrm{~h}$ to detect autonomic or behavioral changes in responses to the extracts. Then the Mortality in each group was observed for $14 \mathrm{~d}$ [10]. The methanolic and aqueous extracts of leaves of Neuracanthus sphaerostachyus were found to be nontoxic at a dose of $1500 \mathrm{mg} / \mathrm{kg}$, orally. Hence, LD cut off value of methanolic and aqueous extract were fixed as $1500 \mathrm{mg} / \mathrm{kg}$. Therefore $1 / 10^{\text {th }}, 1 / 6^{\text {th }}, 1 / 3$ rd of the $\mathrm{LD}_{50}$ cut off value that was approximately 150,250 and 500 $\mathrm{mg} / \mathrm{kg}$ were selected as screening dose for anti-inflammatory activity.

\section{Animal grouping}

Animals were randomly divided into nine groups as normal control, positive control, reference control and test groups of 6 rats as follows:

Group I: normal control received vehicle (normal saline) (1 $\mathrm{ml} / \mathrm{kg}$ ) orally (PO) without colitis induction. Group II: positive control received TNBS in $0.25 \mathrm{ml}$ of $50 \%$ ethanol $(\mathrm{v} / \mathrm{v})$. Group III: reference control received prednisolone $(10 \mathrm{mg} / \mathrm{kg}$, PO) $2 \mathrm{~h}$ after colitis induction and continued for $7 \mathrm{~d}$ thereafter. Group IV, V, and VI: received 3 increasing doses of MENS (methanolic extract of leaves of Neuracanthus sphaerostachyus) at 150,250 , and $500 \mathrm{mg} / \mathrm{kg} \mathrm{PO}, 2 \mathrm{~h}$ after colitis induction and continued for $7 \mathrm{~d}$ thereafter. Group VII, VIII, and IX: received 3 increasing doses of AENS (aqueous extract of leaves of Neuracanthus sphaerostachyus) at 150, 250 , and $500 \mathrm{mg} / \mathrm{kg} \mathrm{PO}, 2 \mathrm{~h}$ after colitis induction and continued for $7 \mathrm{~d}$ thereafter.

\section{Experimental protocol}

All samples, solutions of drugs, and plant extracts were freshly prepared. The extracts were used as a suspension in $0.5 \% \mathrm{v} / \mathrm{v}$ Tween 80 in normal saline $(0.9 \%)$ and administered orally. Animals were fasted overnight and kept under anesthesia prior to the induction of colitis. $10 \mathrm{mg}$ of tri-nitro benzene sulphonic acid (TNBS) dissolved in $0.25 \mathrm{ml}$ of $50 \%$ ethanol $(\mathrm{v} / \mathrm{v})$ and administered through a Teflon cannula inserted $8 \mathrm{~cm}$ into the anus. During and after TNBS administration, rats remained in a head down position until they recover from the anesthesia. Rats from the normal control group will receive $0.25 \mathrm{ml}$ of saline instead of TNBS. Treatments started after $2 \mathrm{~h}$ of TNBS administration and continued daily for 7 days. Animals were 
Indo Global Journal of Pharmaceutical Sciences, 2021; 11(1): 7-14

sacrificed to remove colon for histopathology, macroscopic scoring and biochemical assay $[11,12]$.

\section{Assessment parameters}

\section{Animal body weight and feed intake}

Animal body weight was recorded for $7 \mathrm{~d}$. For the evaluation of the intake of food, a fixed amount of feed was given to the rat every day. The intake of food was calculated by subtracting the remaining feed with the given feed weight.

\section{Macroscopic Scoring}

The animals were sacrificed and the small intestine was removed and opened longitudinally. Gross findings were ranked using the following criteria, 0 - No change mucosa, 1Hyperemia, 2-Single mucosal erosion, 3-Single mucosal erosion, 4-Multiple ulcerations with less than $10 \mathrm{~cm}$, 5Multiple ulcerations with more than $10 \mathrm{~cm}$.

\section{Biochemical Assays}

\section{Colonic lipid peroxides concentration (LPO)}

Lipid peroxidation involves the release of reactive oxygen species leading to mucosal injury. The mucosal injury was measured as thiobarbituric acid reactive substance. $0.5 \mathrm{ml}$ of colonic tissue homogenate was collected and allowed to react with $2 \mathrm{ml}$ of TBA reagent, containing $0.375 \%$ TBA, $15 \%$ trichloroacetic acid and $0.25 \mathrm{~N} \mathrm{HCl}$. Samples were heated for 15 min followed by centrifugation with cooling. The absorbance of the supernatants was measured by spectrophotometer measured at $532 \mathrm{~nm}$.

$$
\text { Concentration }(\mu \mathrm{M})=\frac{\text { Absorbance }}{\text { Molar extinction coefficient }} \times 10^{2}
$$

Myeloperoxidase (MPO) activity

$2 \mathrm{~cm}$ of inflamed tissues of rat colon was removed and the tissue was then rinsed with saline (ice cold) followed by blotted drying. Tissue was homogenized with 10 volumes of potassium phosphate buffer ( $\mathrm{pH} \mathrm{7.4,} \mathrm{ice} \mathrm{cold)} \mathrm{using} \mathrm{tissue}$ homogenizer. The tissue homogenate was centrifuged at 3500 $\mathrm{r} / \mathrm{min}$ for 3 cycles of $10 \mathrm{~min}$ each. The supernatant solution was discarded. $10 \mathrm{ml}$ of cold $50 \mathrm{mM}$ potassium phosphate buffer containing $0.5 \%$ hexadecyl trimethyl ammonium bromide (HETAB) and $10 \mathrm{mM}$ EDTA was then added to the solution. It was subjected to freezing and thawing followed by sonication. Further, the solution was centrifuged at 15,000 $\mathrm{r} / \mathrm{min}$ for $20 \mathrm{~min}$. Myeloperoxidase (MPO) activity was measured spectrophotometrically as follows: Supernatant solution $(0.1 \mathrm{ml})$ was added in $2.9 \mathrm{ml}$ of $50 \mathrm{mM}$ phosphate buffer containing $0.167 \mathrm{mg} / \mathrm{ml}$ O-dianisidine hydrochloride and $0.0005 \% \mathrm{H} 2 \mathrm{O} 2$. The change in absorbance was measured spectrophotometrically at $460 \mathrm{~nm}$.

$$
\text { MPO Activity }=\frac{\mathrm{X}}{\text { Weight of tissue piece taken }}
$$

Where $\mathrm{X}=10 \times \frac{\text { Change in absorbance per minute }}{\text { Vol of supernatant taken in final reading }}$

\section{Estimation of TNF- $\alpha$}

TNF- $\alpha$ (a proinflammatory cytokine) in pg per $\mathrm{ml}$ was estimated with the help of ELISA Reader. The supernatant solution collected previously was used to quantify TNF- $\alpha$. TNF- $\alpha$ (Cayman Chemical, USA) ELISA kit was used. The assay was performed according to the manufacturer's recommendations $[11,13]$.

\section{Histopathological evaluation}

Portions of the inflamed colon were fixed in phosphate buffered formaldehyde formalin solution and embedded in paraffin followed by thin sections with $5 \mu \mathrm{m}$ were prepared (Rotary microtome). Tissues were stained with hematoxylin and eosin and further evaluated by microscopy (Olympus DP74 - 400X) [14].

\section{Statistical analysis}

All values are presented as mean \pm SEM of six animals. Differences between means were assessed by one-way analysis of variance (ANOVA) followed by Dunnett's test. Results were considered as significant at $\mathrm{P}<0.05$.

\section{RESULTS AND DISCUSSION} Animal body weight and feed intake

TNBS treated group (Positive control) exhibits severe anorexia with a decrease in animal body weight and average feed intake as shown in (Table 1). In contrast, groups treated with prednisolone (standard control), MENS and AENS significantly improved body weight and feed intake in dosedependent manner.

\section{Macroscopic Scoring}

The macroscopic study revealed the extensive colonic mucosal injury to colon with the positive control group. During study it was observed that the normal control group showed no lesions of mucosal injury due to the insertion of saline. Treatment with reference drug (prednisolone) as corticosteroid reduced the ulcer score $(p<0.001)$ (Table 1). Oral treatment with MENS and AENS reduced the macroscopic score significantly $(p<0.01)$ as compared to the positive control group.

\section{Biochemical Assays}

Effect of MENS and AENS $(150,250,500 \mathrm{mg} / \mathrm{kg}$, PO) on Colonic Lipid Peroxides concentration (LPO), 
Indo Global Journal of Pharmaceutical Sciences, 2021; 11(1): 7-14

Myeloperoxidase (MPO) and TNF- $\alpha$ is shown in Table.2. The biochemical assay shows that treatment of TNBS leads to extensive damage to colonic mucosa with an increase in colonic LPO, MPO activity, and TNF- $\alpha$ along with the decrease in animal body weight and feed intake. Prednisolone treatment was effective $(\mathrm{p}<0.001)$ in reversing these parameters whereas MENS was found to be more effective than AENS $(\mathrm{p}<0.01)$.

\section{Histopathological evaluation}

The Histopathological changes observed in the normal and treated rat colon are shown in figure 1 - 9. Fig. 1 - Normal colon of rat showed intact mucosa with no change in epithelial surface. Fig. 2 - TNBS treated group exhibits extensively inflamed colonic damage with edema. Fig. 3 - TNBS

Table 1 - Effect of methanolic and aqueous extract of leaves of Neuracanthus sphaerostachyus on animal body weight, feed intake, and macroscopic score.

\begin{tabular}{|c|c|c|c|}
\hline Treatment & $\begin{array}{c}\text { \% Decrease in body } \\
\text { weight }\end{array}$ & Food intake & $\begin{array}{c}\text { Macroscopic score } \\
\text { (points) }\end{array}$ \\
\hline Normal control & - & $162.3 \pm 5.26$ & 0 \\
\hline Positive control & $8.76 \pm 0.54$ & $56.23 \pm 4.48$ & $4.0 \pm 0.10$ \\
\hline $\begin{array}{c}\text { Standard control } \\
10 \mathrm{mg} / \mathrm{kg}\end{array}$ & $1.56 \pm 0.26^{* * *}$ & $148 \pm 3.26^{* * *}$ & $0.56 \pm 0.02 * * *$ \\
\hline MENS $150 \mathrm{mg} / \mathrm{kg}$ & $5.26 \pm 0.45$ & $68.23 \pm 5.63$ & $2.41 \pm 0.18^{*}$ \\
\hline MENS $250 \mathrm{mg} / \mathrm{kg}$ & $2.46 \pm 0.62 * *$ & $96.26 \pm 3.50 * *$ & $1.95 \pm 0.14 * *$ \\
\hline MENS $500 \mathrm{mg} / \mathrm{kg}$ & $1.98 \pm 0.25^{* * *}$ & $140.20 \pm 4.30 * * *$ & $0.96 \pm 0.02 * * *$ \\
\hline AENS $150 \mathrm{mg} / \mathrm{kg}$ & $5.38 \pm 0.46$ & $64.06 \pm 4.09$ & $2.89 \pm 0.14$ \\
\hline AENS $250 \mathrm{mg} / \mathrm{kg}$ & $3.41 \pm 0.42 *$ & $90.50 \pm 4.68 *$ & $2.18 \pm 0.16^{*}$ \\
\hline AENS $500 \mathrm{mg} / \mathrm{kg}$ & $2.12 \pm 0.64 * *$ & $132.21 \pm 3.89 * *$ & $1.64 \pm 0.09 * *$ \\
\hline
\end{tabular}

Table 2 - Effect of methanolic and aqueous extract of leaves of Neuracanthus sphaerostachyus on colonic LPO, MPO activity and TNF- $\alpha$ level.

\begin{tabular}{|c|c|c|c|}
\hline Treatment & $\begin{array}{c}\text { Colonic LPO } \\
\text { concentration } \\
(\mu \mathrm{g} / \mathrm{g} \text { of wet tissue) }\end{array}$ & MPO(U/gm) & TNF $-\alpha(\rho g / m l)$ \\
\hline Normal control & $54.21 \pm 2.12$ & $0.195 \pm 0.023$ & $214.92 \pm 0.348$ \\
\hline Positive control & $92.41 \pm 0.47$ & $1.048 \pm 0.132$ & $357.22 \pm 0.586$ \\
\hline $\begin{array}{c}\text { Standard control } \\
10 \mathrm{mg} / \mathrm{kg} \\
\end{array}$ & $58.56 \pm 0.23 * * *$ & $0.236 \pm 0.021 * * *$ & $216.79 \pm 1.24 * * *$ \\
\hline MENS $150 \mathrm{mg} / \mathrm{kg}$ & $86.62 \pm 1.32$ & $0.925 \pm 0.054$ & $351.56 \pm 0.79^{\mathrm{ns}}$ \\
\hline MENS $250 \mathrm{mg} / \mathrm{kg}$ & $78.24 \pm 0.56^{*}$ & $0.756 \pm 0.087 *$ & $311.01 \pm 0.765 * *$ \\
\hline MENS $500 \mathrm{mg} / \mathrm{kg}$ & $64.58 \pm 0.45^{* *}$ & $0.376 \pm 0.058 * *$ & $248.20 \pm 0.181 * * *$ \\
\hline AENS $150 \mathrm{mg} / \mathrm{kg}$ & $89.41 \pm 0.21$ & $0.988 \pm 0.087$ & $349.52 \pm 0.85^{\mathrm{ns}}$ \\
\hline AENS $250 \mathrm{mg} / \mathrm{kg}$ & $81.23 \pm 1.56$ & $0.790 \pm 0.084$ & $318.20 \pm 0.171 * *$ \\
\hline AENS $500 \mathrm{mg} / \mathrm{kg}$ & $70.54 \pm 0.23 *$ & $0.398 \pm 0.064 * *$ & $261.64 \pm 0.355^{* * *}$ \\
\hline
\end{tabular}


Indo Global Journal of Pharmaceutical Sciences, 2021; 11(1): 7-14

- Histopathological evaluation

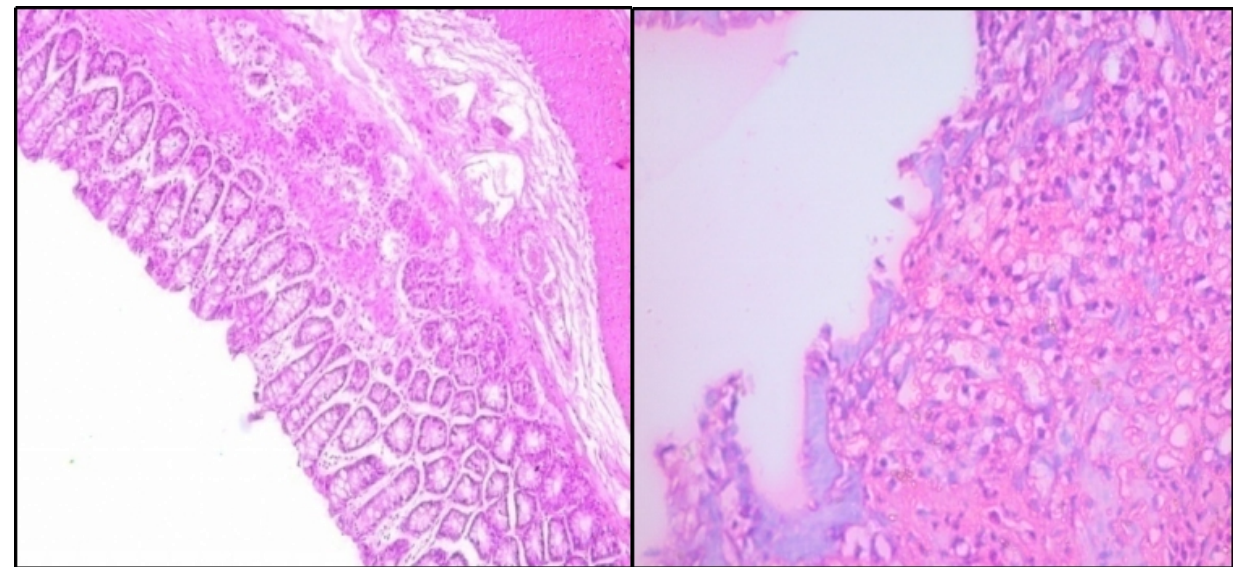

Fig (1) Histopathological slide of normal control group
Fig (2) Histopathological slide of Positive control (TNBS) group

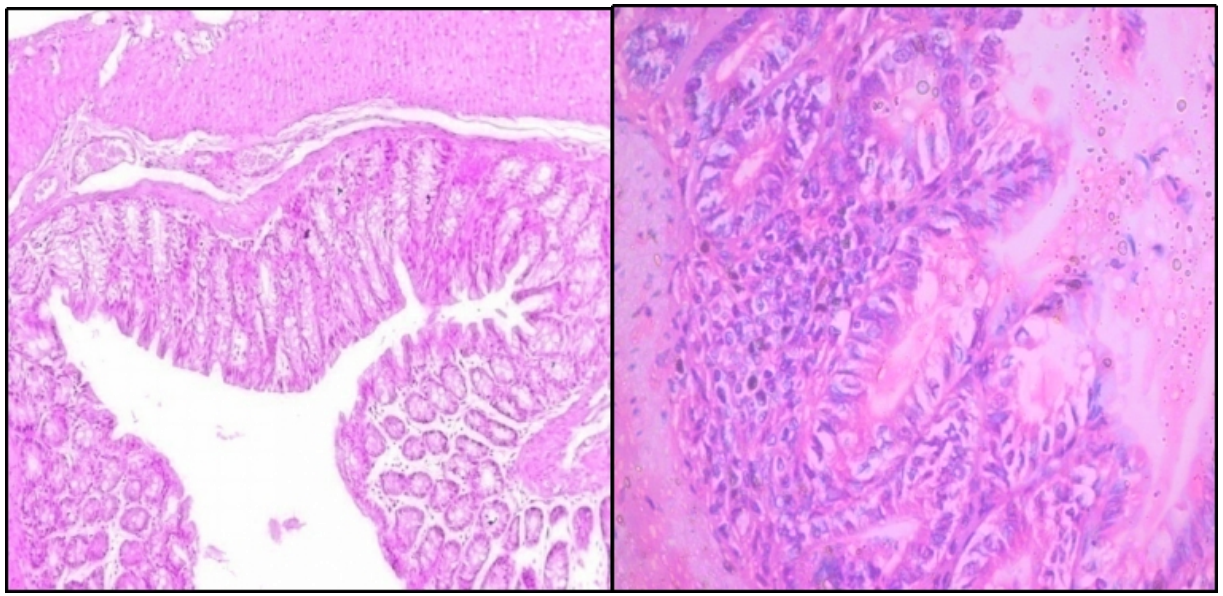

Fig (3) Histopathological slide of standard Control (Prednisolone) group

Fig (4) Histopathological slide of group receiving methanolic extract of $150 \mathrm{mg} / \mathrm{kg}$

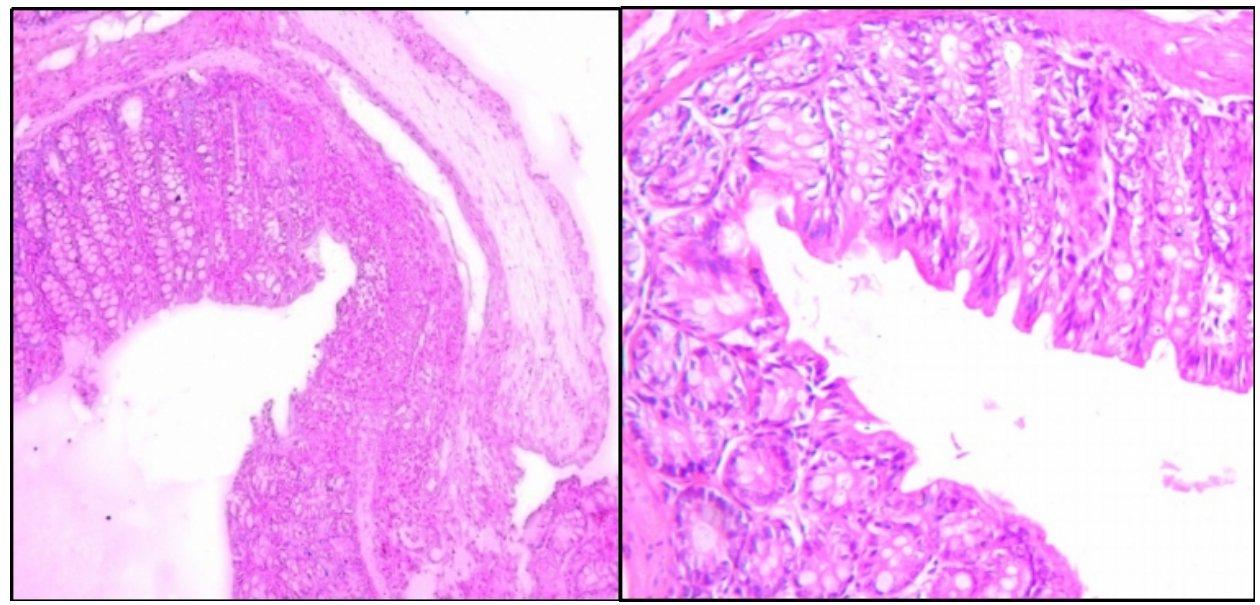

Fig (5) Histopathological slide of group receiving methanolic extract of $250 \mathrm{mg} / \mathrm{kg}$
Fig (6) Histopathological slide of group receiving methanolic extract of $500 \mathrm{mg} / \mathrm{kg}$ 
Indo Global Journal of Pharmaceutical Sciences, 2021; 11(1): 7-14

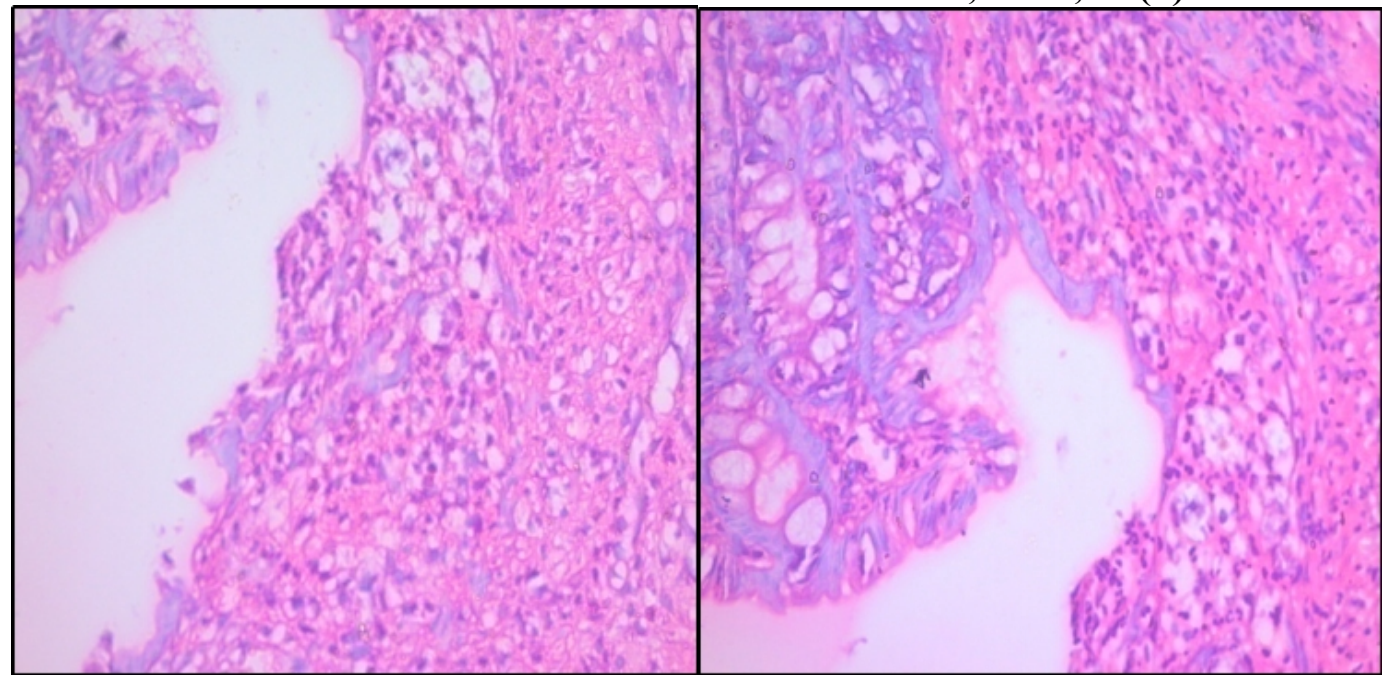

Fig (7) Histopathological slide of group receiving aqueous extract of $150 \mathrm{mg} / \mathrm{kg}$

Fig (8) Histopathological slide of group receiving aqueous extract of $250 \mathrm{mg} / \mathrm{kg}$

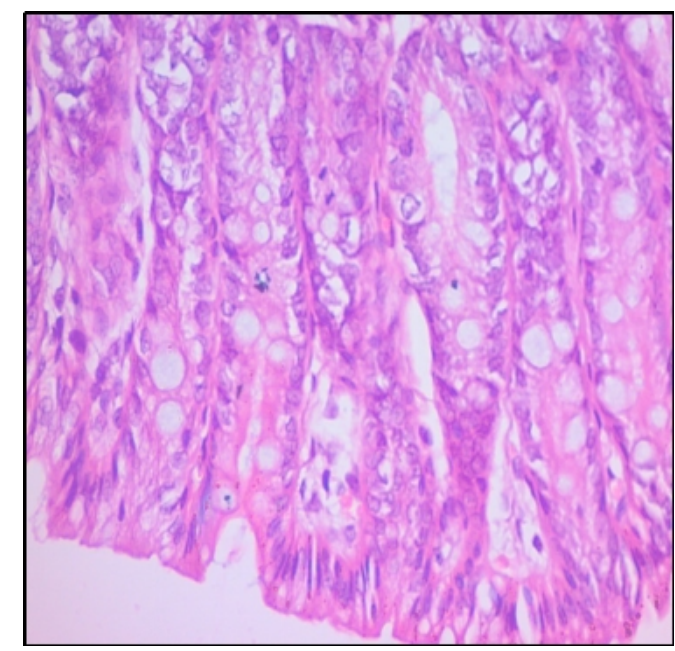

Fig (9) Histopathological slide of group receiving aqueous extract of $500 \mathrm{mg} / \mathrm{kg}$

TNBS induced colitis mimics the condition associated with human IBD and considered as the best model to check the anti-ulcerogenic potential of crude extract [15]. Administration of TNBS in the colon leads to sustained chronic inflammation and ulceration. Tissue damage may results into increased no. of polymorphonuclear leukocytes, colonic wall thickening and formation of granuloma followed by increased vascular permeability making disturbances in intestinal immune defense mechanism. TNBS involves specific characteristics like one-time administration, the damage is reproducible, inexpensive, sustained inflammation with cellular infiltration and ulcer, makes TNBS most prominent for ulcerogenic activity. Inflammation for longer duration permits a specified time interval for the evaluation of herbal extracts for their beneficial potential. Positive control group demonstrated the extensive damage to the mucosal architecture with cellular infiltration. Cellular infiltration allows movement of neutrophils and monocytes into colonic tissues. Locally produced cytokines are responsible for the migration of neutrophils and monocytes leading to the generation of reactive oxygen species or metabolites, responsible for the mucosal damage. Histological study exhibits a change in mucosal pattern allows assessing various parameters with different doses of crude extract.

Inflammation involves the release of MPO, and it represents ongoing neutrophilic activity. Measurement of MPO activity directly correlated with the activity of neutrophils in 
Indo Global Journal of Pharmaceutical Sciences, 2021; 11(1): 7-14

inflammation. TNF- $\alpha$ is a pro-inflammatory cytokine secreted by $\mathrm{T} \& \mathrm{~B}$ lymphocytes as well as from mast cells and plays a crucial role in the development of IBD [16]. The mucosal injury may be a result of lipid peroxidation and involves the release of ROS (reactive oxygen species).

Neuracanthus sphaerostachyus is traditionally used in western ghat and it shows the presence of vanillic acid, syringic acid, melilotic acid and, 6-OH luteolin [7]. In another study it shows the presence of luteolin and quercetin and it will be reported under the phytochemical profile in future. Various studies are reported with luteolin and quercetin for its potential to inhibit lipid peroxidation, myeloperoxidase activity and, $\mathrm{TNF}-\alpha$, a proinflammatory mediator.

Luteolin is a potent inhibitor of lipid peroxidation and arachidonic acid release from cell membrane inhibits release of various prostaglandins, leukotrienes and, interleukins. Luteolin inhibits mast cell degranulation through its mast cell stabilizing property. Luteolin and quercetin have been reported as an anti-inflammatory agent [17-22]. Major cases of IBD may involve the inflammation with mucosal damage due to the release of various free radicals and accumulation of lymphocytes and monocytes being a target for luteolin and quercetin with its beneficial application in current allopathic medicine system.

\section{CONCLUSION}

With these pre-clinical results, it can be concluded that methanolic and aqueous extracts of Neuracanthus sphaerostachyus Dalz. leaves are significantly effective in the treatment of colonic mucosal damage caused by TNBS and can be used in the treatment of IBD due to the presence of flavonoids like luteolin and quercetin. However, these findings should be extrapolated through human trials before its application in clinical cases.

\section{CONFLICTS OF INTEREST}

The authors declare that there is no conflict of interest regarding the publication of this paper.

\section{ACKNOWLEDGEMENT}

None

\section{DATA AVAILABILITY}

Not declared.

\section{FUNDING SOURCE}

Not declared

\section{REFERENCES}

1. Patil, M.V., Kandhar, A.D., Bhise S.D. anti-inflammatory effect of daucus carota root on experimental colitis in rats. Int. Journal of Pharmacy and Pharma. Sciences., 2012; 4(1): 18-25.

2. Biradar, S.M., et al. Protective effects of ethanolic extract of Ageratum conyzoides on experimental induced inflammatory bowel disease. J. of pharmacol. and toxic., 2011; 6(8): 664-678.

3. Katzung, B.G. Basic and clinical pharmacology, $10^{\text {th }}$ Edn., McGraw Hill Companies Inc.,New Delhi, India, 2007.

4. Shanahan, F., Inflammatory bowel disease: immunodiagnostics, immunotherapeutics and ecotherapeutics. Gastroenterology, 2001; 120: 622-635.

5. Khare, C.P. Indian medicinal plants, An illustrated dictionary, Springer publication. 2007.

6. Punjani, B.L., Kumar, V., Traditional medicinal plant remedies to treat cough and asthmatic disorders in the Aravalli ranges in North Gujarat, India, J. of Nat. Reme., 2002; 2(2): 173-178.

7. Daniel, M., Sabnis, S.D., Chemosystematics of some Indian members of the Acanthaceae. Proe. Indian Acad. Sci. (Plant Sci.), 1987; 97(4): 315-332.

8. Indian Pharmacopoeia. Government of India, $2^{\text {nd }}$ ed., New Delhi, 1966; 33-4.

9. Committee for the Purpose of Control and Supervision on Experiments on Animals. CPCSEA guidelines for laboratory animal facility, Indian J of Pharmacol. 2003; 35: 257-274.

10. http://www.oecd.org/chemicalsafety/riskassessment/1948378.pdf

11. Costa, C.A. et al. Anti-inflammatory effects of Brazilian ginseng on TNBS-induced intestinal inflammation: Experimental evidence. Inter Immunopharmaco 2015; 28: 459-69.

12. Patil, N.R. et al., Screening of Mandarin Oil on Indomethcin Induced Inflammatory Bowel Disease in Wistar Rats. I J Pharma Edu and Re, 2014; 48.

13. https://www.caymanchem.com/pdfs/500850.pdf/21/7/2018

14. Jagtap, A.G., Shrike, S.S., Phadke, A.S. Effect of polyherbal formulation on experimental models of inflammatory bowel diseases. J Ethnopharmacol. 2004; 90(2): 195-204.

15. Morris, G.P., Rebeiro, L., Herride, M.M., Szewczuk, M., Depew, W. An animal model of chronic granulomatous inflammation of stomach and colon, Gastroenterology, 1985; 86: 1188.

16. Prakash, O. et al. Effect of combination of thalidomide and sulfasalazine in experimentally induced inflammatory bowel disease in rats. Indian journal of Experimental Biology. 2011; 49: 672-78.

17. Elliott, M., Chithan K., Theoharis C. The Effects of Plant Flavonoids on Mammalian Cells: Implications for Inflammation, Heart Disease, and Cancer. The American Society for Pharmacology and Experimental Therapeutics. Pharmacol Rev, 2000 ; 52: 673-751.

18. Ufuk, $\mathrm{O}$ et al. Relationship Between Chemical Structure and Antioxidant Activity of Luteolin and Its Glycosides Isolated from Thymus sipyleus subsp. sipyleus var. Sipyleus. Rec. Nat. Prod. 2011; 5(1):12-21.

19. Theoharis, C. Luteolin as a therapeutic option for multiple sclerosis. J Neuroinfl, 2009; 6(29): 1-3.

20. Cai, Q., Rahn, R.O., Zhang, R. Dietary flavonoids, quercetin, luteolin and genistein, reduce oxidative DNA damage and lipid peroxidation and quench free radicals. Cancer Letters, 1997; 119(1): 99-107.

21. Patel, N.G., Patel, K.G., Patel K.V., Gandhi T.R. Validated HPTLC Method for Quantification of Luteolin and Apigenin in Premna mucronata Roxb., Verbenaceae. Adv in Pharmaco Sci, 2015: 1-7. 
Indo Global Journal of Pharmaceutical Sciences, 2021; 11(1): 7-14

22. Dong, H. et. al. Enhanced antioxidant activity, antibacterial activity and hypoglycemic effect of luteolin by complexation with manganese(II) and its inhibition kinetics on xanthine oxidase. The Royal Society of Chemistry, 2017; 7: 5338553395.

Indo Global Journal of Pharmaceutical Sciences( ISSN 2249 1023; CODEN- IGJPAI; NLM ID: 101610675) indexed and abstracted in CrossRef (DOI Enabling), CNKI, EMBASE (Elsevier), National Library of Medicine (NLM) Catalog (NCBI), ResearchGate, Publons (Clarivate Analytics), CAS (ACS), Index Copernicus, Google Scholar and many more. For further details, visit http://iglobaljournal.com 